\title{
APPLICATION OF FINITE ELEMENT METHOD FOR DETERMINING LOADS FOR THE NEW METHOD OF ACOUSTIC FATIGUE TESTING OF AIRCRAFT STRUCTURES
}

\author{
Antoni Niepokólczycki, Andrzej Szot \\ Institute of Aviation, Warsaw, Poland
}

\begin{abstract}
Summary
For aircraft structures the failures due to acoustic fatigue are very important, particularly for new supersonic or short take-off aircraft. The majority of acoustic fatigue life test methods are based on the reproduction of noise acting on the structure - in reverberation chambers or progressive wave tubes. The method described in this paper is based on the reproduction of dynamic response of the structure subjected to random acoustic loading.
\end{abstract}

\section{INTRODUCTION}

The problem of acoustic fatigue of aircraft structures appeared in the early 50's of the last century as one of the major problems in a jet aircraft. As speed, size and weight of modern aircraft have increased so has the significance of this problem.

Resistance to acoustic fatigue of aircraft structures is one of the main criteria for their evaluation. This is evidenced by the aircraft design regulations which treat the acoustic and classic structure fatigue issues equally. This means that the random vibrating aircraft structural components must be tested in order to determine their fatigue life due to this load.

In recent years we have seen the growing interest in acoustic fatigue problems. This is due to the focus on supersonic aircraft and short take off and landing aircraft. An emphasis is also placed on the resistance to vibration of composite structures, with particular attention to: composite composite and composite - metal connections.

In studying the phenomenon of structure acoustic fatigue, laboratory tests in simulated noise conditions play a key role. However, at high acoustic loads and large structures surface area the simulating device power needed to achieve a broadband simulation significantly exceeds the power of the available equipment.

It is therefore necessary to develop a test method that does not require to faithfully reproduce the acoustic field acting on the structure. This method will rely not on the reconstruction of the load acting on the structure (e.g. noise load), but on the reconstruction of the structure dynamic response to this load. The essence of the method is to replace the actual broadband non-harmonic excitation by polyharmonic excitation, containing main resonance frequencies of the vibrating structures.

The most important issue in the investigations performed with the presented method is simulating the actual vibrations in such a way that the actual fatigue effects of the real and simulated vibrations are identical at every moment of the test. This is a fundamental requirement for application of this method. The development of a criterion by which the selection of structure significant free vibrations will be made while the above condition is met, was the main goal of the research project, whose realization is described in [9]. 

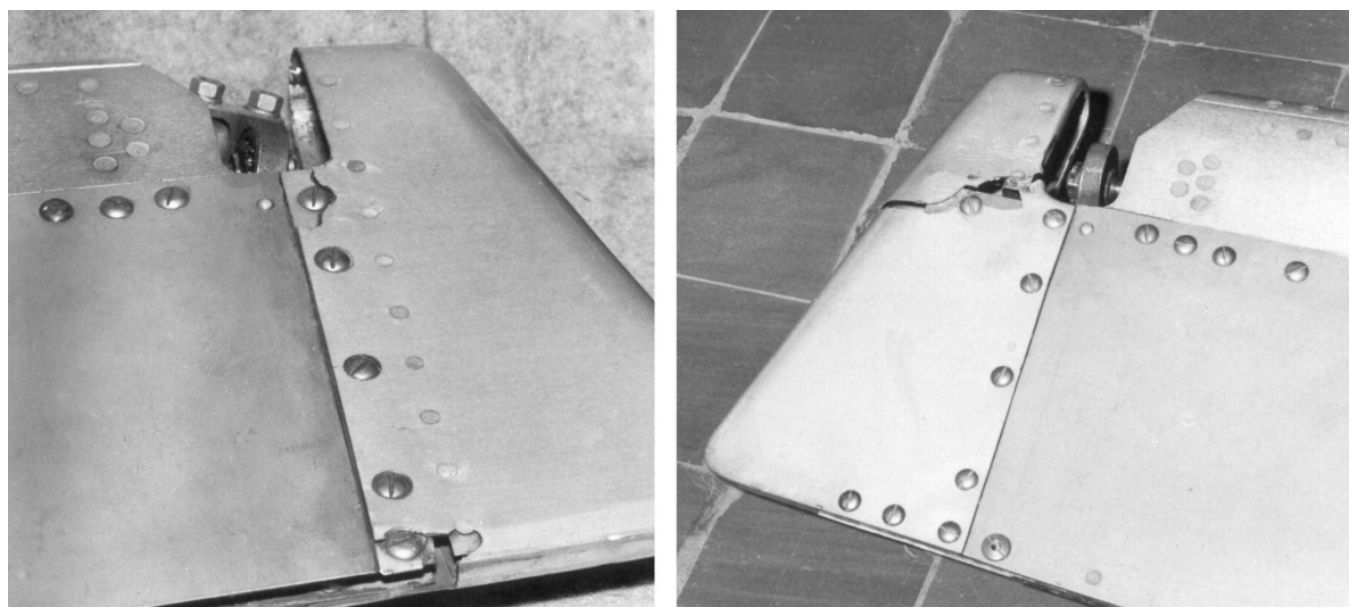

Fig. 1. Examples of cracks in the structure of the airplane elevator due to acoustic fatigue.

\section{ASSUMPTIONS OF THE RESEARCH METHOD}

Aircraft structures consist of many mechanical components such as plates, beams, bolts, rivets, etc. These elements have different shapes and are made of different materials. Theoretical estimation of acoustic durability of the whole structure is thus very difficult, and in most cases even impossible. However, you can resolve this issue, as is the case in the presented method, by the full structure laboratory testing, using modern equipment to induce vibrations.

The basic assumptions of the method being developed are as follows:

I. to the non-harmonic excitation, the broadband structure responds with its free vibrations with the intensity depending on the excitation intensity - as shown by the vibration analysis in the frequency domain.

II. Vibrations of a finite structure can be considered as the sum of a number of its free vibrations, each of which is performed with a specific frequency $\omega_{\mathrm{r}}$ and is referred in the mode $\mathrm{S}_{\mathrm{r}}(\mathrm{x})$ satisfying the boundary conditions and is possible to excite independently of the others. In accordance with the above the summary of vibration amplitudes at the point $\mathrm{x}$ can be defined as follows [1]:

$$
\xi(t, x)=\sum_{r} \xi_{r}(t) S_{r}(x)
$$

where $\xi_{\mathrm{r}}$ is the amplitude of vibration at the reference point of the $\mathrm{r}$-th free vibration mode $S_{r}(x)$.

In a situation where the vibrations of one mode dominate significantly over the others, the mean square of vibration amplitude is:

$$
\left\langle\xi^{2}(x)\right\rangle \cong\left\langle\xi_{r}^{2}(t)\right\rangle S_{r}^{2}(x)
$$

If some of free vibration modes are excited to a comparable extent, then:

$$
\left\langle\xi^{2}(x)\right\rangle=\sum_{r} \sum_{s}\left\langle\xi_{r}(t) \xi_{s}(t)\right\rangle S_{r}(x) S_{s}(x)=\sum_{r}\left\langle\xi_{r}^{2}(t)\right\rangle S_{r}^{2}(x)+\sum_{r \neq s} \sum\left\langle\xi_{r}(t) \xi_{s}(t)\right\rangle S_{r}(x) S_{s}(x)
$$

i.e. the mean square amplitude of vibration at the point $\mathrm{x}$ is the sum of the average squares of the amplitudes resulting from each of the modes separately and the cross-correlation between the modes.

Assuming orthogonality of vibration mode the second component of the sum is equal to zero and then:

$$
\left\langle\xi^{2}(x)\right\rangle \cong \sum_{r}\left\langle\xi_{r}^{2}(t)\right\rangle S_{r}^{2}(x)
$$


III. In the vibration response of the structure to the acoustic load the finite number of free vibrations occur, which are essential from the viewpoint of fatigue strength.

IV. Time to the fatigue damage of the vibrating structure, $\mathrm{T}$, determined by using the linear cumulative damage hypotheses is equal to:

$$
T=\frac{1}{N_{0} \int_{0}^{\infty} \frac{p(\sigma)}{N(\sigma)} d(\sigma)}
$$

where:

$N_{0}$ - the average frequency of vibration

$p(\sigma)$ - probability density curve of stress amplitude maxima

$N(\sigma)$ - The number of stress cycles to failure

$\sigma$ - the peak amplitude of the stresses.

\section{DETERMINATION OF ACOUSTIC LOADS}

Assumptions

- The acoustic load, due to jet noise, will be theoretically determined based on the ENGINEERING SCIENCES DATA UNIT (ESDU), Item Number 72002 „The Estimation of Near-Field Sound Pressure Levels Due To Jet Noise",

- $80 \%$ of the load energy is accumulated in the frequency range $0 \div 2200 \mathrm{~Hz}$.

The spectrum of the load, calculated using these assumptions is shown below in Figure 2

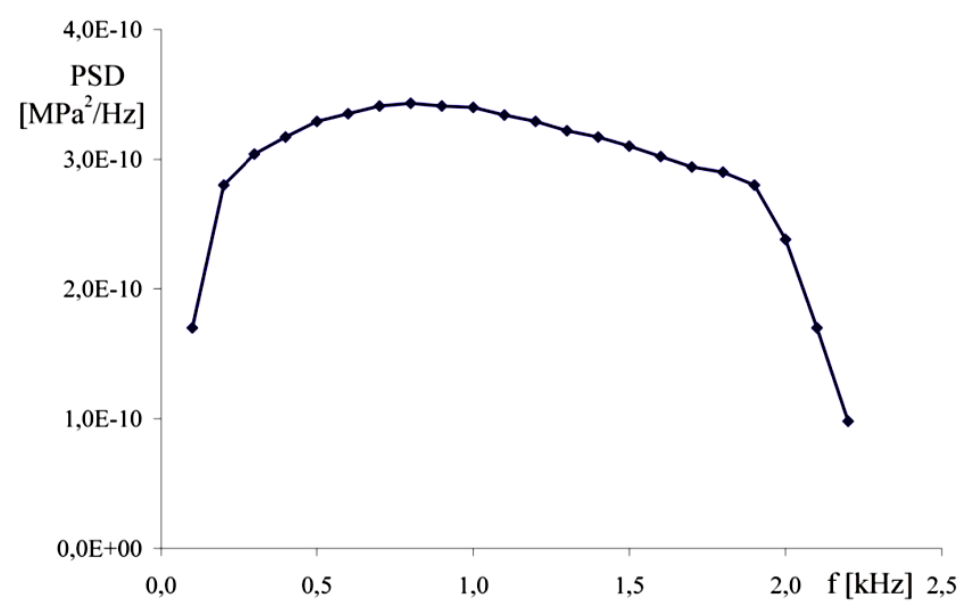

Fig. 2. Distribution of PSD for assumed acoustic load.

\section{CHARACTERISTICS OF THE ANALYZED STRUCTURES}

Calculations were performed for the two variants of empennage design samples and two variants of the horizontal elevator of the I-22 Iryda jet trainer. Discrete models of the structures analyzed are shown in Fig. 3

\section{Design sample.}

Option A is a fragment of the horizontal tail measuring $470 \times 300 \mathrm{~mm}$, made of duralumin. The specimen consists of a sheet of the thickness of $0.6 \mathrm{~mm}$ and the ribs riveted to it of 20x28x1 mm. Damping Factor: $\eta=2 \mathrm{C} / \mathrm{C}_{0}=0.004$. 
Option B - specimen as in option A, the skin is made of epoxy-glass composite of the thickness of $1 \mathrm{~mm}$. Damping coefficient for the composite: $\eta=0.006$.

\section{Elevator}

Option A - a classic design with a metal skin with the thickness of $0.8 \mathrm{~mm}$.

Option B - design using a honeycomb core filling in the trailing edge space between the skins.
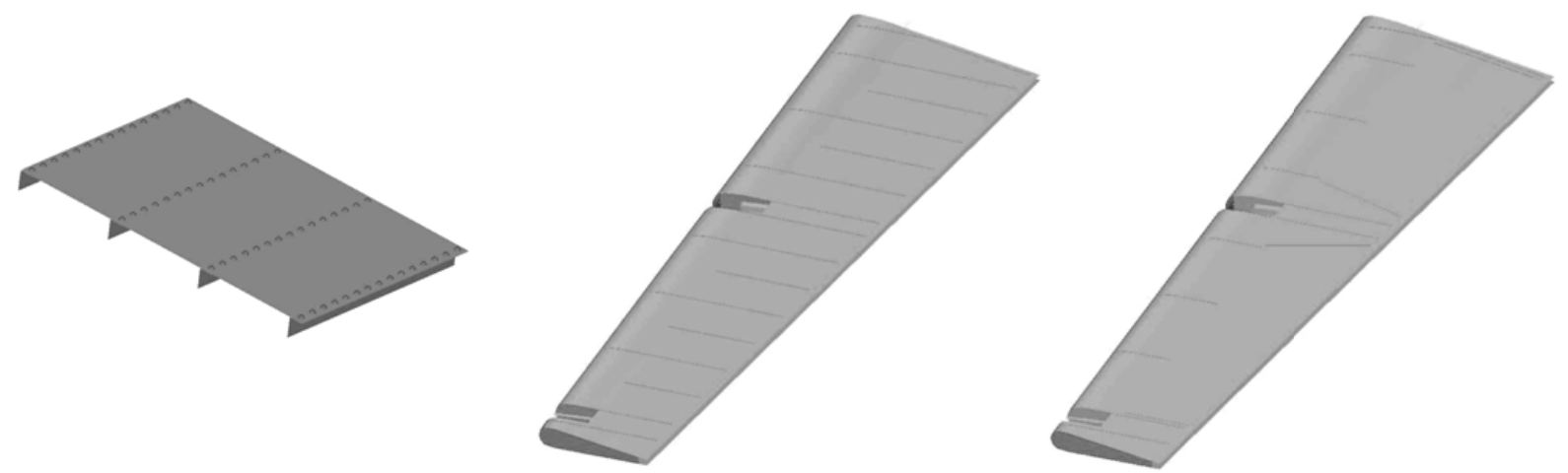

Fig. 3. Model views: the emmpenage sample (left) and elevator of the classical design (middle) and the honeycomb core design (right). The lines of division into elements are removed

\section{THE FLAT SKIN SPECIMENS ANALYSIS PROCEEDINGS}

The discrete specimen models were loaded with a broadband acoustic load, as described in p. 3 As a result of FEM calculations, firstly the free structure frequencies were obtained, then the RMS and PSD distributions of stresses in the global coordinate system, in the entire range of the load spectrum. For the selected point of the structure, shown in Fig. 4, the PSD and RMS stresses were plotted in the frequency range $0 \div 2000 \mathrm{~Hz}$. The average frequency of vibrations $\mathrm{N}_{0}$ was calculated. The results of calculations for the metal specimens are presented in Figs. 5, 6 and 7 and in Table 2.

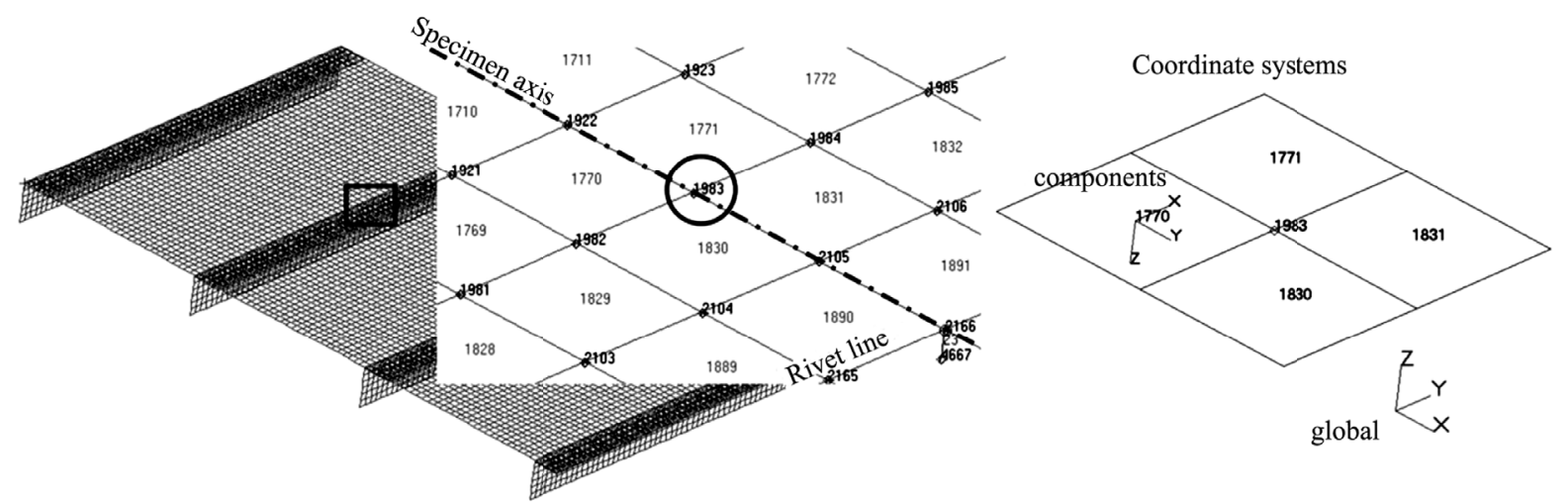

Fig. 4. Skin specimen. The location of the analyzed node and coordinate systems. 

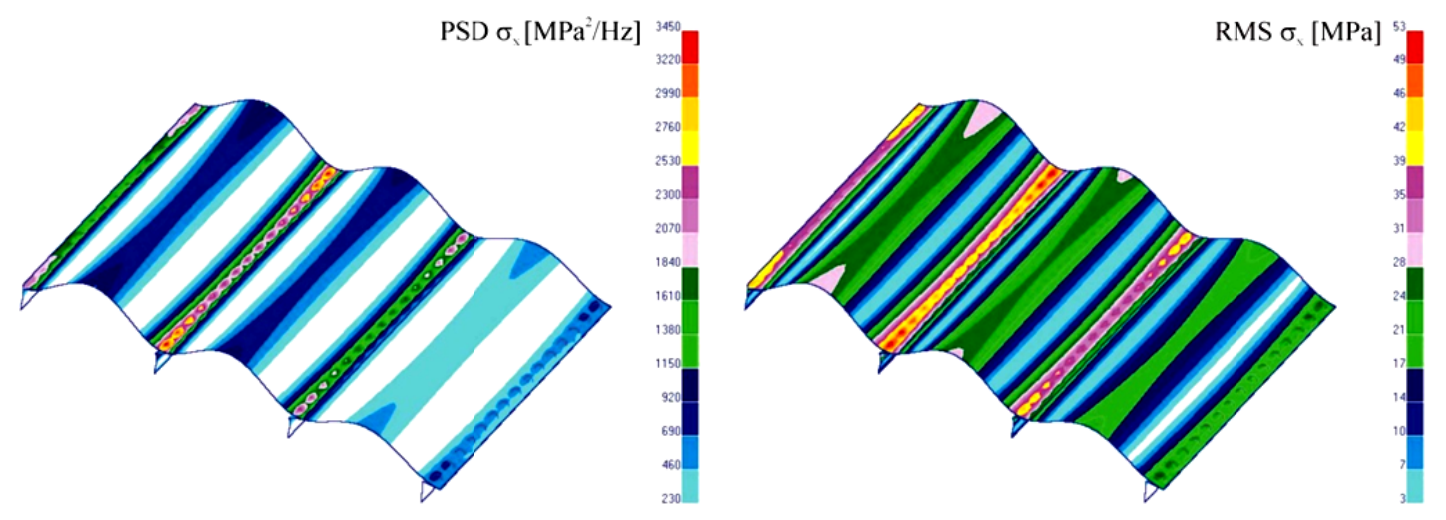

Fig. 5. Distribution of PSD (left) and RMS (right) $\sigma_{x}$ stresses in global coordinate system, in a model of a metal specimen, at a frequency of $216 \mathrm{~Hz}$. The calculation step: $d f=1 \mathrm{~Hz}$.
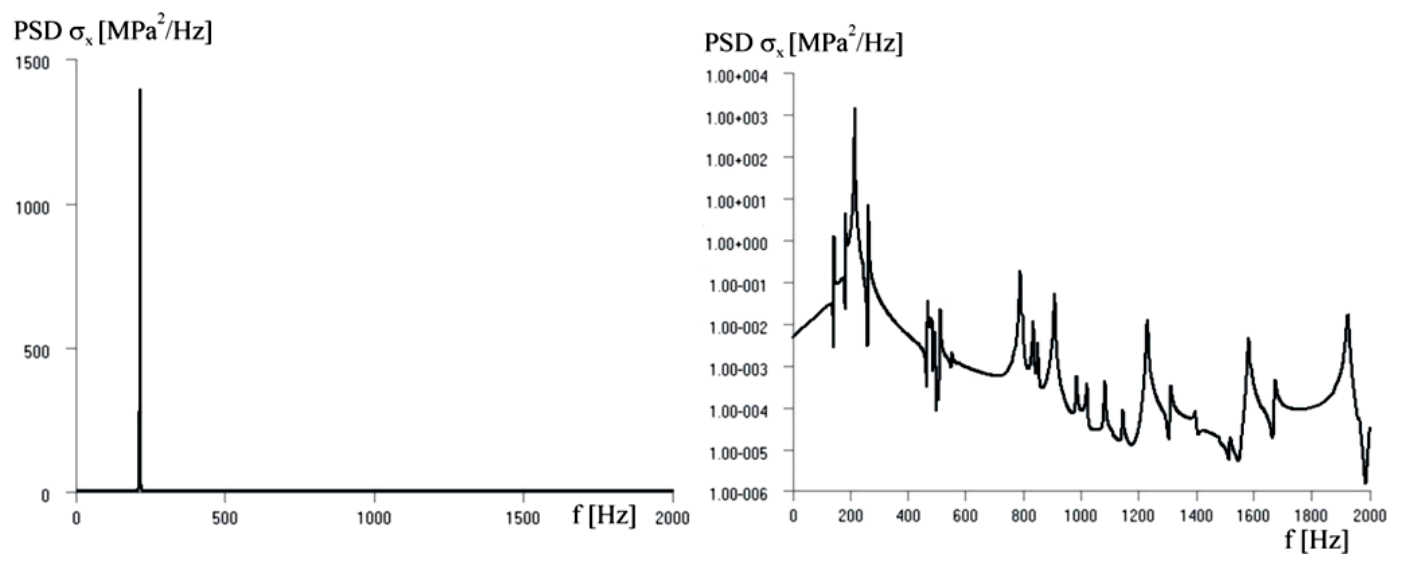

Fig. 6. Distribution PSD of $\sigma_{x}$ stresses in the global coordinate system, in the 1983 node of the metal model specimen, in the frequency range 0-2000 $\mathrm{Hz}$, the y axis on the left - linear, on the right - in the logarithmic system. The calculation step $d f=1 \mathrm{~Hz}$.

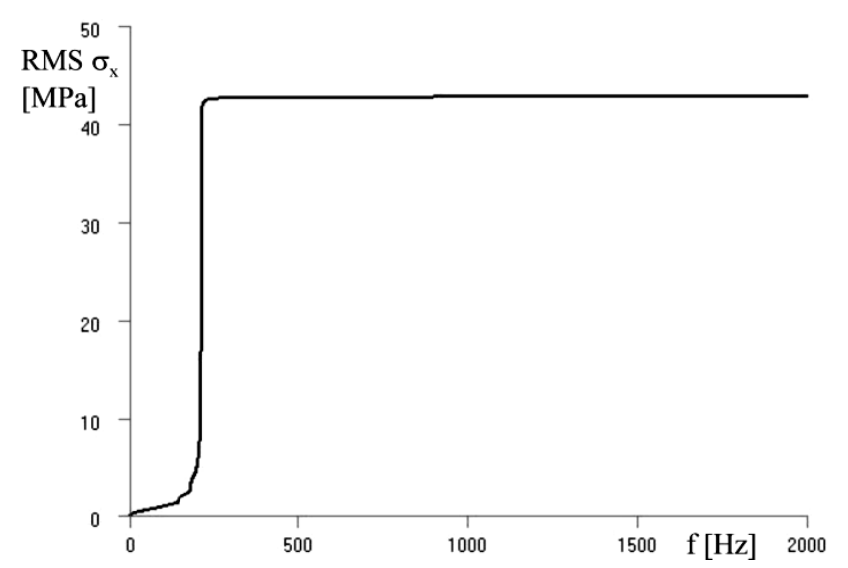

Fig. 7. Distribution of the RMS $\sigma_{x}$ stresses in the 1983 node of the metal model specimen in the frequency range 0-2000 $\mathrm{Hz}$. The calculation step $d f=1 \mathrm{~Hz}$.

Table 1. The results of the vibrations analyses for the 1983 node of the skin specimens

\begin{tabular}{|l|c|c|c|c|}
\hline \multirow{2}{*}{ Specimen } & $\mathrm{N}_{0}$ & $\mathrm{f}_{0 \mathrm{~d}}$ & $\mathrm{RMS} \sigma_{\mathrm{x}}$ & $\mathrm{PSD}_{\mathrm{d}} \sigma_{\mathrm{x}}$ \\
\cline { 2 - 5 } & \multicolumn{2}{|c|}{$\mathrm{Hz}$} & $\mathrm{MPa}$ & $\mathrm{MPa}^{2} / \mathrm{Hz}$ \\
\hline metal & 217,91 & 215,9 & 54,20 & 1572,0 \\
\hline composite & 193,73 & 161,2 & 28,59 & 356,2 \\
\hline
\end{tabular}


The data obtained as a result of these analyses, in real conditions is obtained in the course of vibration measurements of acoustically loaded structures. The next step is the selection of resonances important for structure fatigue. This was achieved by approximating the real vibration spectrum by the box-type spectrum containing the same amount of energy centered around the resonant frequencies - Fig. 8. The method is described in the following publications [6.7].
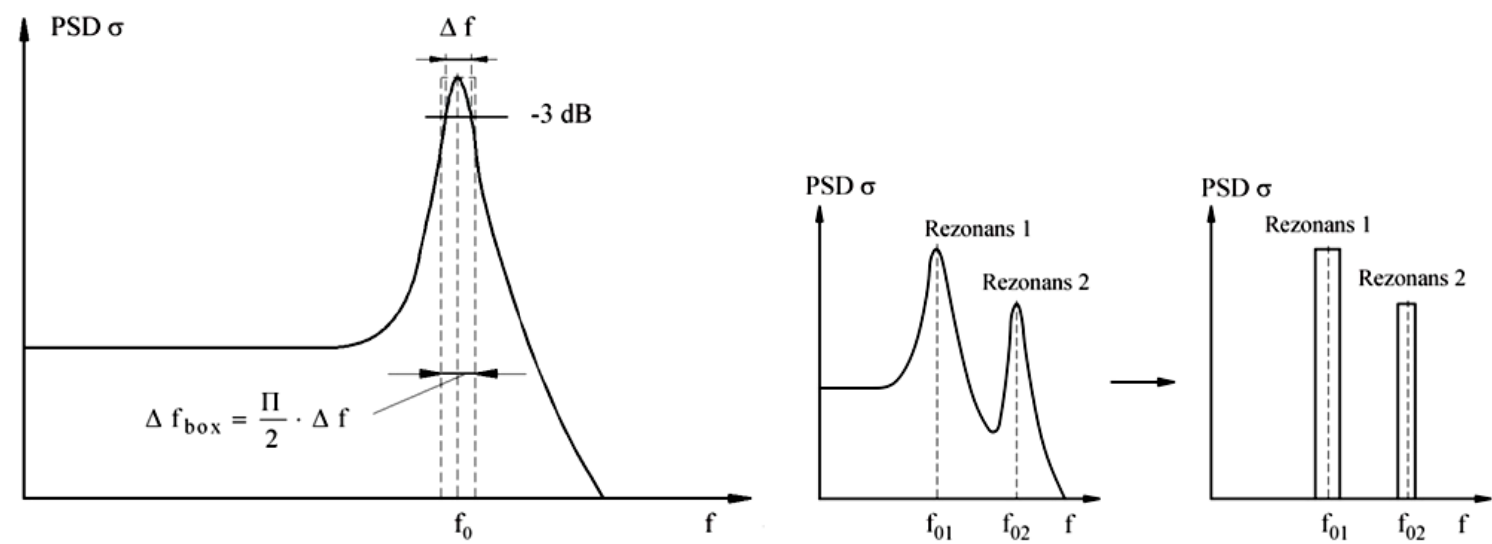

Fig. 8. The method of replacing the vibration spectrum of a single degree of freedom system by a rectangular spectrum containing the same amount of energy concentrated around the resonant frequency (left) and a typical vibration spectrum of two degrees of freedom system and a corresponding spectrum of a rectangular type (middle and right).

In Table 2 below, are presented all the relevant resonance frequencies for both samples, which were selected for analysis. The dominant resonance is in the first place. For each specified resonance, there were determined: the value of the PSD stresses $\sigma_{\mathrm{y}}$, the rectangle area $\Delta \mathrm{F}$ and the value of $\beta_{n}$ equal to the ratio of $n$-th resonance area to the area of the dominant resonance, then the value of $\alpha_{\mathrm{n}}$.

For each of the designated values $\alpha_{n}$ the both values of $\beta_{n}$ were calculated that may lead to the achievement of the same values of $\alpha_{n}$. In each of the cases of two specimens examined, the baseline values $\beta_{\mathrm{n}}$ are smaller than the values designated subsequently. It can therefore be assumed that the effect of other resonances than the resonance frequency of $215.9 \mathrm{~Hz}$ (for a metal specimen) and $161.2 \mathrm{~Hz}$ (for a composite specimen) are negligible, and both systems can be treated as single degree-of-freedom systems.

Table 2. Resonances considered in the analysis of skin specimens

\begin{tabular}{|c|c|c|c|c|c|c|c|c|c|}
\hline \multicolumn{5}{|c|}{ Metal specimen } & \multicolumn{5}{c|}{ Composite specimen } \\
\hline $\mathrm{f}_{0}$ & $\mathrm{PSD}_{\mathrm{x}}$ & $\Delta \mathrm{F}$ & $\beta_{\mathrm{n}}$ & $\alpha_{\mathrm{n}}$ & $\mathrm{f}_{0}$ & $\mathrm{PSD}_{\mathrm{x}}$ & $\Delta \mathrm{F}$ & $\beta_{\mathrm{n}}$ & $\alpha_{\mathrm{n}}$ \\
\hline $\mathrm{Hz}$ & $\mathrm{MPa}^{2} / \mathrm{Hz}$ & $\mathrm{MPa}^{2}$ & \multicolumn{2}{|c|}{-} & $\mathrm{Hz}$ & $\mathrm{MPa}^{2} / \mathrm{Hz}$ & $\mathrm{MPa}^{2}$ & \multicolumn{2}{c|}{-} \\
\hline 215,90 & 1572 & 1357,58 & 1 & 1 & 161,22 & 356,2 & 344,559 & 1 & 1 \\
\hline 143,75 & 1,7700 & 1,01775 & 0,000750 & 0,9998 & 186,37 & 0,944 & 1,05560 & 0,003064 & 0,9997 \\
\hline 184,53 & 7,7500 & 5,72043 & 0,004214 & 0,9997 & 324,82 & 0,009 & 0,01754 & $5,09 \mathrm{E}-05$ & 0,9995 \\
\hline 467,77 & 0,0306 & 0,05726 & $4,22 \mathrm{E}-05$ & 0,9994 & 760,78 & 0,009 & 0,04108 & 0,000119 & 0,9492 \\
\hline 789,30 & 0,0526 & 0,16607 & 0,000122 & 0,9817 & 822,50 & 1,340 & 6,61290 & 0,019192 & 0,1576 \\
\hline 908,47 & 0,0586 & 0,21294 & 0,000157 & 0,9582 & 857,38 & 0,017 & 0,08745 & 0,000254 & 0,8429 \\
\hline 1230,27 & 0,0134 & 0,06594 & $4,86 \mathrm{E}-05$ & 0,9542 & 1562,60 & 0,013 & 0,12188 & 0,000354 & 0,2588 \\
\hline 1925,36 & 0,0167 & 0,12861 & $9,47 \mathrm{E}-05$ & 0,6348 & - & - & - & - & - \\
\hline
\end{tabular}


The primary criterion for assessing the suitability of the proposed method for acoustic fatigue testing of elements of aircraft structures is that the fatigue effects of actual and simulated vibrations should be identical at every stage of the test. To meet the above criterion using the accepted model of linear accumulation of damage, the compliance of the RMS stresses and vibration energy values must be ensured during the test. Then time to vibrating structure fatigue damage can be determined from the relationship:

$$
\frac{T_{r}}{T_{s}}=\frac{N_{0 s}}{N_{0 r}}
$$

where

$T_{r}, T_{s}$ - time to the fatigue structure damage respectively under real and simulated loads, $N_{0 r}, N_{0 s}$ - the average frequency of vibrations in real and simulated conditions respectively.

The conditions of simulated narrowband load determined for tested specimens and received resulting specimens vibration parameters at the analysed point of skin are given below in Table 3 .

Table 3. Specimens simulated load conditions

\begin{tabular}{|c|c|c|c|c|c|}
\hline \multirow{2}{*}{ Specimen } & \multicolumn{3}{|c|}{ Excitation } & \multicolumn{3}{c|}{ Structure response } \\
\cline { 2 - 6 } & Frequency range & $\mathrm{PSD}$ & $\mathrm{RMS} \sigma_{\mathrm{x}}$ & $\mathrm{PSD}_{\mathrm{d}} \sigma_{\mathrm{x}}$ & $\mathrm{N}_{0 \mathrm{~s}}$ \\
\cline { 2 - 6 } & $\mathrm{Hz}$ & $\mathrm{MPa}^{2} / \mathrm{Hz}$ & $\mathrm{MPa}$ & $\mathrm{MPa}^{2} / \mathrm{Hz}$ & $\mathrm{Hz}$ \\
\hline Metal & $213,9-217,9$ & 458 & 54,2 & 2513 & 215,9 \\
\hline Composite & $159,2-163,2$ & 434 & 28,59 & 640,88 & 161,2 \\
\hline
\end{tabular}

\section{THE ANALYSIS OF THE AIRCRAFT HORIZONTAL EMMPENAGE STRUCTURE}

\subsection{The results of the numerical analysis}

The elevator models described in p. 4 have been subjected to acoustic load, as specified in p. 3 . As a result of FEM calculations similar to described in p. 5 for skin specimens, the free frequencies of structures were obtained. For selected points (Fig. 9), calculations of RMS and PSD stresses were made in the frequency range $0 \div 1000 \mathrm{~Hz}$. The average frequency of vibrations $\mathrm{N}_{0}$ was calculated.
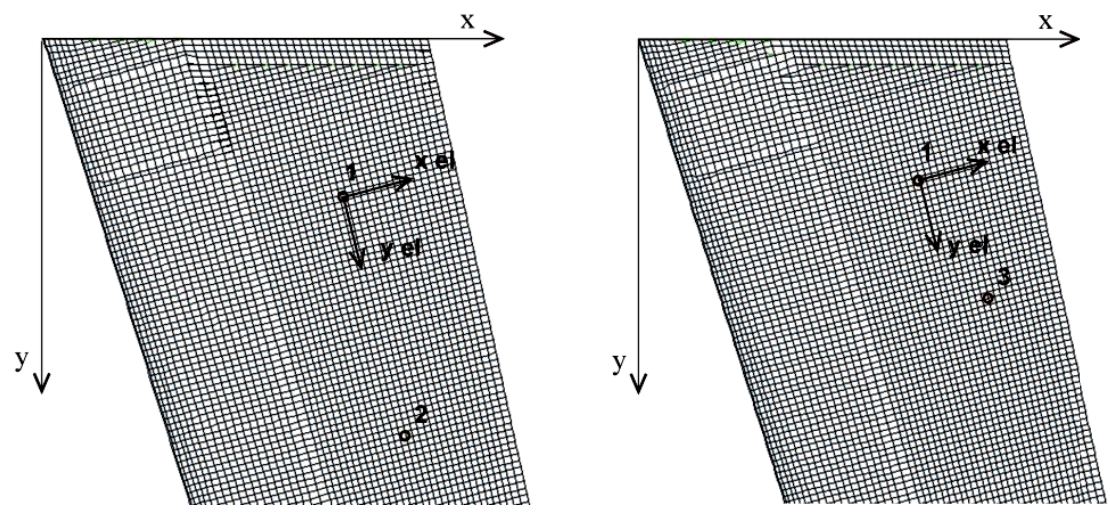

Fig. 9. The location of the analyzed points on the bottom of the elevator, left-the elevator of classic design, right - the elevator with a honeycomb core. The location of points compatible with the location of points adopted in the work [11]. The global and components coordinate systems were shown. 


\section{The classic elevator}

In the $0 \div 1000 \mathrm{~Hz}$ frequency range 140 resonances were identified. The dependency of the PSD and the RMS stresses $\sigma_{y}$ on the frequency in the components coordinate system at point 1 of the model is shown in Fig. 10 and 11.
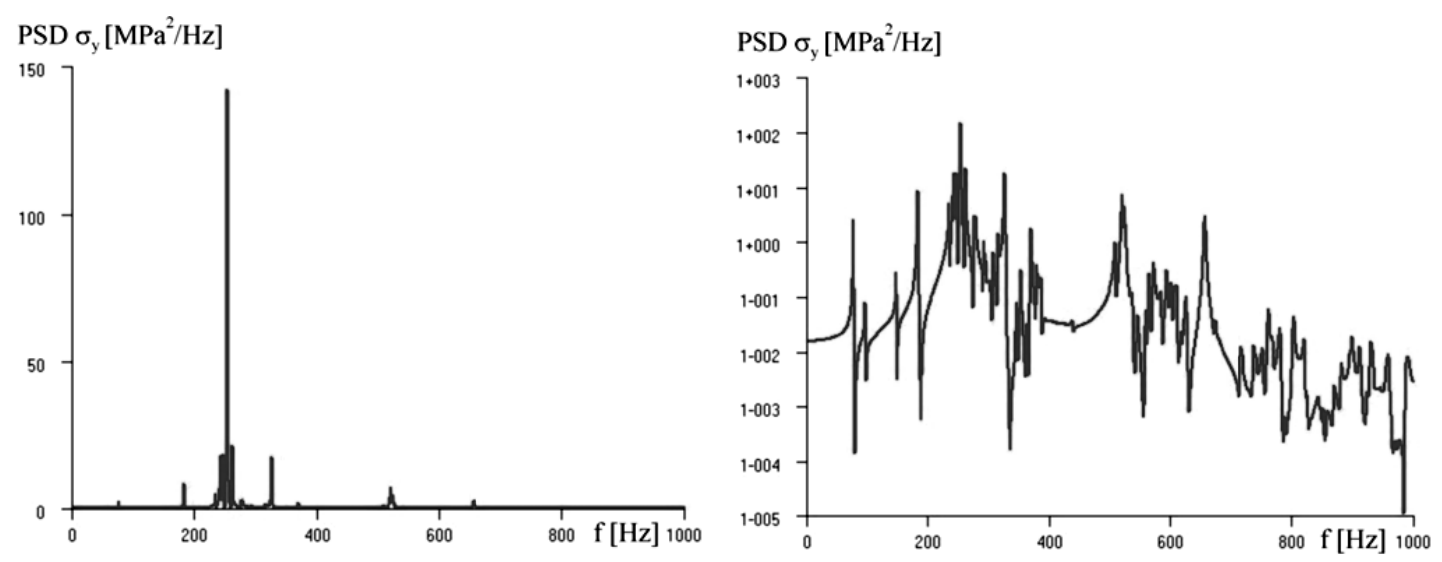

Fig. 10. The distribution of PSD $\sigma_{y}$ stresses in the components coordinate system at point 1 of the lower skin of the classical model of the elevator, in the frequency range $0-1000 \mathrm{~Hz}$, the y axis on the left linear, on the right-logarithmic. The calculation step $d f=1 \mathrm{~Hz}$.

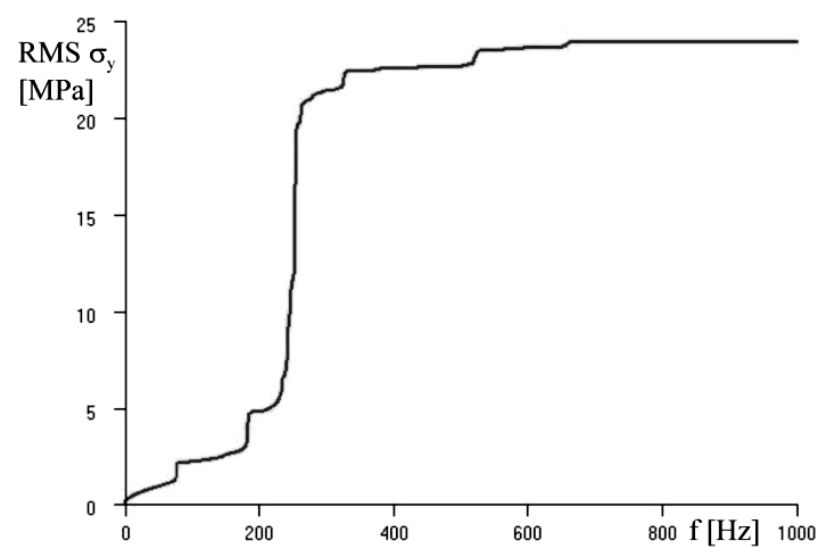

Fig. 11. The distribution of RMS $\sigma_{v}$ stresses in the components coordinate system at point 1 of the lower skin of the classical model of the elevator, in the frequency range $0-1000 \mathrm{~Hz}$. The calculation step $d f=1 \mathrm{~Hz}$.

The results of the model lower skin vibration analysis at selected points, where 11 mayor resonances have been taken into account, are given in Table 4 below.

Table 4. The results of the classic elevator model lower skin vibration analysis at selected points.

\begin{tabular}{|c|c|c|c|c|}
\hline \multirow{2}{*}{ Point No. } & $\mathrm{N}_{0}$ & $\mathrm{f}_{0 \mathrm{~d}}$ & $\mathrm{RMS} \sigma_{\mathrm{y}}$ & $\mathrm{PSD}_{\mathrm{d}} \sigma_{\mathrm{y}}$ \\
\cline { 2 - 5 } & \multicolumn{2}{|c|}{$\mathrm{Hz}$} & $\mathrm{MPa}$ & $\mathrm{MPa}^{2} / \mathrm{Hz}$ \\
\hline 1 & 248,9 & 253,7 & 23,70 & 184 \\
\hline 2 & 253,2 & 253,7 & 36,44 & 683 \\
\hline
\end{tabular}




\section{The elevator with a honeycomb core}

In the frequency range $0-1000 \mathrm{~Hz}$ at the measurement points, 30 resonances were identified, out of which 5 major were selected for further analysis. The results of the elevator model vibration analysis at selected points of the lower skin for selected resonances are shown in Table 5

Table 5. The results of honeycomb elevator model vibration analysis at selected points of the lower skin

\begin{tabular}{|c|c|c|c|c|}
\hline \multirow{2}{*}{ Point No. } & $\mathrm{N}_{0}$ & $\mathrm{f}_{0 \mathrm{~d}}$ & $\mathrm{RMS} \sigma_{\mathrm{y}}$ & $\mathrm{PSD}_{\mathrm{d}} \sigma_{\mathrm{y}}$ \\
\cline { 2 - 5 } & \multicolumn{2}{|c|}{$\mathrm{Hz}$} & $\mathrm{MPa}$ & $\mathrm{MPa}^{2} / \mathrm{Hz}$ \\
\hline 1 & 144,7 & 166,5 & 1,92 & 2,31 \\
\hline 3 & 159,5 & 166,5 & 2,44 & 2,31 \\
\hline
\end{tabular}

\subsection{The analysis of acoustic vibrations}

At the next stage of work, for both types of the elevator design, the resonances of importance for structure fatigue were selected. This was done as described in p. 5

Table 6 shows the resonance frequencies selected as the most relevant for the analysis. Analyzed were the measurement points at which the strains had the highest values. They are: point 2 for the classic elevator and the point 3 for the honeycomb elevator (Fig. 9). At the top of the table, the dominant resonances were shown.

Table 6. The summary of the results of the acoustic vibrations analysis of both elevator designs

\begin{tabular}{|c|c|c|c|c|c|c|c|c|c|}
\hline \multicolumn{5}{|c|}{ Classic elevator, point 2} & \multicolumn{5}{|c|}{ Honeycomb elevator, point 3} \\
\hline $\mathrm{f}_{0}$ & $\operatorname{PSD} \sigma_{\mathrm{y}}$ & $\Delta \mathrm{F}$ & $\beta_{\mathrm{n}}$ & $\alpha_{n}$ & $\mathrm{f}_{0}$ & $\operatorname{PSD} \sigma_{\mathrm{y}}$ & $\Delta \mathrm{F}$ & $\beta_{\mathrm{n}}$ & $\alpha_{n}$ \\
\hline $\mathrm{Hz}$ & $\mathrm{MPa}^{2} / \mathrm{Hz}$ & $\mathrm{Hz}$ & 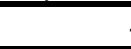 & & $\mathrm{Hz}$ & $\mathrm{MPa}^{2} / \mathrm{Hz}$ & $\mathrm{Hz}$ & - & \\
\hline 253,7 & 683,300 & 708,531 & 1 & 1 & 166,5 & 4,9490 & 3,42970 & 1 & 1 \\
\hline 77,2 & 6,121 & 1,971 & 0,00278 & 0,99772 & 85,1 & 0,5500 & 0,19784 & 0,057680 & 0,9703 \\
\hline 183,8 & 12,895 & 9,749 & 0,01376 & 0,99695 & 102,9 & 0,6060 & 0,27030 & 0,078810 & 0,9724 \\
\hline 261,6 & 121,249 & 133,131 & 0,18800 & 0,99950 & 817,1 & 0,0231 & 0,07740 & 0,022566 & 0,1655 \\
\hline
\end{tabular}

As a result of the classic elevator vibrations analysis, it can be assumed that the effect of resonances other than the dominant resonance frequency $-253.7 \mathrm{~Hz}$, is negligible and, according to the assumptions of the proposed method, the system can be regarded as a single degree-of-freedom system. Similarly, in the case of the honeycomb elevator, the analysis showed that the system can be treated as a single degree-of-freedom system of the resonance frequency of $166.5 \mathrm{~Hz}$.

\subsection{The selection of the narrowband load}

The narrowband simulated load conditions designated for the elevator and the resulting vibration data received at the analyzed points of skin are given below in Table 7.

Table 7. Conditions of the elevators simulated load.

\begin{tabular}{|l|c|c|c|c|c|}
\hline \multirow{2}{*}{ Elevator } & \multicolumn{3}{|c|}{ Excitation } & \multicolumn{3}{c|}{ Structure response } \\
\cline { 2 - 6 } & Frequency range & $\mathrm{PSD}$ & $\mathrm{RMS} \sigma_{\mathrm{y}}$ & $\mathrm{PSD}_{\mathrm{d}} \sigma_{\mathrm{y}}$ & $\mathrm{N}_{0 \mathrm{~s}}$ \\
\cline { 2 - 6 } & $\mathrm{Hz}$ & $\mathrm{MPa}^{2} / \mathrm{Hz}$ & $\mathrm{MPa}$ & $\mathrm{MPa}^{2} / \mathrm{Hz}$ & $\mathrm{Hz}$ \\
\hline classical & $252,7-254,7$ & 450,3 & 36,44 & 1185 & 253,7 \\
\hline honeycomb & $165,5-167,5$ & 279,4 & 2,44 & 7,08 & 166,5 \\
\hline
\end{tabular}




\section{CONCLUSIONS}

The acoustic vibrations analysis of the simple fragments of the flat skin has led to the conclusion that the vibration response is dominated by only one component, and the impact of the others is negligible.

Similarly, the acoustic vibrations analysis of the complex structure fragments of the jet's horizontal empennage, located in the zone of strong acoustic influence of the jet noise, has led to the conclusion that vibration response is dominated by only one component, and the impact of the others is negligible. This conclusion is confirmed by the vibration measurements of the aircraft elevators on Iryda I-22 airplane, as described in work [11].

Results obtained in the course of the analytical verification suggest that the proposed test method can be applied to acoustic fatigue tests. However, the final answer as to the possibility of the use of the method can only be obtained by its experimental verification.

\section{LITERATURE}

[1] Acoustical Fatigue in Aerospace Structures. (1965). In Walter J. Trapp \& Donald M. Forney (Eds.). In: Proceedings of the $2^{\text {nd }}$ International Conference. Dayton, Ohio, April 29 - May 1. Syracuse, New York: Syracuse University Press.

[2] Bendat, J. S. (1958). Principles and Applications of Random Noise Theory. New York: John Wiley \& Sons Inc.

[3] Bendat, J. S., \& Piersol, A. G. (1976). Metody analizy i pomiaru sygnałów losowych [in Polish]. Warsaw: PWN.

[4] Beranek, L. L. (1971). Noise and Vibration Control. New York: McGraw-Hill Book Company.

[5] Broch, J. T. (1963). Effects of Spectrum Non-linearities upon the Peak Distribution of Random Signals. Denmark: B \& K.

[6] Broch, J. T. (1968). Peak Distribution Effects in Random Load Fatigue. Denmark: B \& K.

[7] Broch, J. T. (1968). On the Damaging Effects of Vibration. Denmark: B \& K.

[8] Niepokolczycki, A. (1995). Wprowadzenie do zmęczenia akustycznego elementów konstrukcji lotniczych. Kwartalnik Mechanika, 14(4). Kraków: Akademia GórniczoHutnicza im. Stanisława Staszica.

[9] Niepokolczycki, A, \& Szot, A. (2007). Opracowanie nowej metody wyznaczania trwałości zmęczeniowej struktur lotniczych poddanych działaniu obciażeń akustycznych. Sprawozdanie merytoryczne z realizacji Projektu Badawczego nr 4 T12D 020 27. Warszawa: Instytut Lotnictwa.

[10] Parszewski, Z. (1982). Drgania i dynamika maszyn [in Polish]. Warsaw: WNT.

[11] Instytut Lotnictwa (1990). Pomiary i porównanie naprężeń na pokryciu sterów wysokości wzbudzanych praca silnika odrzutowego. Sprawozdanie Instytutu Lotnictwa nr 8/BWW2/90. Warszawa: Instytut Lotnictwa. 